\title{
Treatment of the neurogenic bladder in spina bifida
}

\author{
Tom P. V. M. de Jong • Rafal Chrzan • Aart J. Klijn • \\ Pieter Dik
}

Received: 28 August 2007 / Revised: 26 December 2007 / Accepted: 15 January 2008 /Published online: 19 March 2008

(C) IPNA 2008

\begin{abstract}
Renal damage and renal failure are among the most severe complications of spina bifida. Over the past decades, a comprehensive treatment strategy has been applied that results in minimal renal scaring. In addition, the majority of patients can be dry for urine by the time they go to primary school. To obtain such results, it is mandatory to treat detrusor overactivity from birth onward, as upper urinary tract changes predominantly start in the first months of life. This means that new patients with spina bifida should be treated from birth by clean intermittent catheterization and pharmacological suppression of detrusor overactivity. Urinary tract infections, when present, need aggressive treatment, and in many patients, permanent prophylaxis is indicated. Later in life, therapy can be tailored to urodynamic findings. Children with paralyzed pelvic floor and hence urinary incontinence are routinely offered surgery around the age of 5 years to become dry. Rectus abdominis sling suspension of the bladder neck is the first-choice procedure, with good to excellent results in both male and female patients. In children with detrusor hyperactivity, detrusorectomy can be performed as an alternative for ileocystoplasty provided there is adequate bladder capacity. Wheelchair-bound patients can manage their bladder more easily with a continent catheterizable
\end{abstract}

Electronic supplementary material The online version of this article (doi:10.1007/s00467-008-0780-7) contains supplementary material, which is available to authorized users.

T. P. V. M. de Jong · R. Chrzan · A. J. Klijn · P. Dik ( $\bowtie)$ Pediatric Renal Center, Department of Pediatric Urology, University Children's Hospital, UMCU,

P.O. Box 85090, 3508 AB Utrecht, The Netherlands

e-mail: p.dik@umcutrecht.nl stoma on top of the bladder. This stoma provides them extra privacy and diminishes parental burden. Bowel management is done by retrograde or antegrade enema therapy. Concerning sexuality, special attention is needed to address expectations of adolescent patients. Sensibility of the glans penis can be restored by surgery in the majority of patients.

Keywords Spina bifida - Surgical treatment - Incontinence . Renal function · Bladder augmentation · Bladder-neck sling · Dryness $\cdot$ Antimuscarinic

\section{Introduction}

The incidence of spina bifida worldwide still ranges from $0.3-4.5$ per 1,000 births. Renal scarring and renal failure have been important issues in spina bifida literature over the years, with reported death due to renal failure up to $20 \%$ in the first year of life. The incidence of renal damage is nearly $100 \%$ in patients with an overactive pelvic floor (detrusor/sphincter dyssynergia; DSD) when not adequately treated. It is important to realize that renal damage starts early in life, within the first 6 months. In contrast to a few decades ago, we can now assure parents of children with a neurogenic bladder that renal function can be preserved provided they comply with the treatment regime [1-14].

To prevent renal damage, urological and nephrological treatment of a neurogenic bladder should start immediately after birth. Modern treatment provides the opportunity to convert a high-pressure bladder with functional urethral obstruction based on neuropathic detrusor/sphincter dyssynergia into a low-pressure reservoir that is safe for the upper urinary tracts $[15,16]$. The objectives in the urological management of patients with spina bifida are 
(1) preservation of renal function; (2) quality of life, preferably with urinary dryness by school age; and (3) independence at an older age with respect to bladder and bowel management. Finally, sexuality in the spina bifida patients is an underestimated problem.

Initial approach for the management of spina bifida

To preserve renal function, low bladder pressure must be maintained from birth. The status of pelvic floor activity must be assessed shortly after birth to ascertain whether a child is at risk for high detrusor pressures. At first presentation after birth, inspection of the anal sphincter, closed or open, gives an impression of the status of the pelvic floor: overactive or paralyzed. Approximately 50\% of children with spina bifida aperta and $25 \%$ of children with occult spinal dysraphism have a detrusor/sphincter dyssynergia that carries a serious risk of early upper urinary tract damage by high bladder pressures and urinary tract infections (UTIs). It is important to realize that after closure of the back, pelvic floor behavior can change from paralyzed to overactive in the first 2-3 months of life. That is a reason to delay the first urodynamic study (UDS) until 2 months after birth.

\section{Clean intermittent catheterization}

In principle, all newborn patients are put on clean intermittent catheterization (CIC), oxybutynin, and chemoprophylaxis (trimethoprim $2 \mathrm{mg} / \mathrm{kg}$ once daily) immediately after closure of the back. By doing so, safe pressures in the lower urinary tract can be obtained in most patients. In most patients, bladder volume and compliance remain satisfactory for years. In patients with DSD, this approach has also reduced the need for bowel augmentation of the bladder from $90 \%$ to less than $5 \%$. Of course, it is still a matter of discussion whether it is necessary to perform CIC from birth onward in all patients. In patients with proven pelvic floor paralysis, it is also possible to wait until after surgery to make the patient continent. However, it can be a tedious affair to teach CIC to an 8-year-old. Parents of these children are advised to catheterize at least twice daily to maintain the habit of CIC. CIC was introduced for neurogenic bladders in 1972 [17-20]. Parents and other caregivers carry out CIC in the first $8-9$ years of life: if the children show sufficient dexterity, they take up this task themselves after this age. After birth, CIC is carried out with self-lubricating $8-\mathrm{F}$ catheters. The size of the catheter depends on the patient's age; the aim is always to use the largest possible catheter to obtain optimal bladder emptying.

\section{Antimuscarinic therapy}

Oxybutynin is best started together with CIC immediately after closure of the back. Other antimuscarinic agents have not yet been registered for pediatric use. This subject is more elaborately described in the section "Overactive detrusor".

Infection prophylaxis

In principle, all patients are put on low-dose chemoprophylaxis, mostly trimethoprim $2 \mathrm{mg} / \mathrm{kg}$ per day. In case of breakthrough infections, nitrofurantoin or ciprofloxacin can be used. Symptomatic infections are treated intravenously with amoxicillin/clavulanic acid and gentamicin until the result of bacterial culture is known. Many centres stop prophylaxis after the age of 1 year, and approximately $50 \%$ of patients seem to do well without prophylaxis. Scientific proof is lacking on this subject. To obtain such proof, we are doing a multicenter randomized study with half of the patients on prophylaxis and half without.

\section{Specific needs}

Overactive pelvic floor

From birth, patients with an overactive pelvic floor generally become dry with the help of oxybutynin and CIC. Every year, UDS are carried out to check bladder activity, capacity, and compliance. Patients are given ultrasound scans for upper-tract dilatation and renal growth. A wait-and-see policy is adopted when bladder capacity is normal for age and end-filling detrusor pressures are $30 \mathrm{cms} \mathrm{H}_{2} \mathrm{O}$ or less. When bladder compliance is insufficient, with end-filling pressures of more than $30 \mathrm{cms}$, an autoaugmentation or detrusorectomy can reduce the pressure. Augmentation by ileocystoplasty or colocystoplasty is inevitable in patients with serious overactivity in combination with poor bladder compliance and low capacity. Both operations can be performed at any age and can be combined with other procedures to obtain better urinary continence to facilitate CIC and/or to reduce UTIs (reflux) [21].

\section{Paralyzed pelvic floor}

Patients with a paralyzed pelvic floor are incontinent for urine. Their upper urinary tracts are safe as long as the paralytic pelvic floor is left untreated. They need bladderneck surgery to become dry. If bladder capacity and compliance are insufficient, surgery can be combined with 
autoaugmentation of the bladder (detrusorectomy) or (rarely) with clam ileocystoplasty or colocystoplasty.

Overactive detrusor muscle

If UDS reveals detrusor overactivity, patients are treated with antimuscarinics to increase bladder capacity, even if detrusor pressures are safe. Life-long suppression of detrusor overactivity is required in patients with an overactive neuropathic bladder. In some patients, overactivity can be treated surgically by detrusorectomy or ileocystoplasty. In spina bifida, rhizotomies (interruption of spinal roots) are not yet being used routinely to cure overactivity, but they seem to be a promising alternative. Ideally, we would like to start a protocol with neonatal rhizotomies during the first back closure, but so far, practical and ethical considerations have prevented us from doing this. Antimuscarinic therapy is the gold standard for pharmaceutical therapy of neuropathic detrusor overactivity. Oxybutynin has proven to be inexpensive and effective and can be taken orally, intravesically, and transdermally. Several new antimuscarinic agents have been introduced, which may prove valuable in the future.

Repeated injection therapy of the bladder with $300 \mathrm{U}$ of botulinum toxin can be an alternative to antimuscarinic therapy. This therapy effectively suppresses detrusor contractions for 6-9 months. Injections need to be repeated at a 6- to 9-month interval. Adverse effects, even after repeated injection therapy, have not been reported. The long-term effects have yet to be established $[22,23]$.

\section{Surgical procedures}

\section{Timing of surgery}

There is no age-related contraindication for any operation. Thus, indication for surgery is made in mutual agreement with the child's parents or with the patients themselves after the age of 11 years. The combination of high bladder pressures and vesicoureteral reflux can sometimes force intervention as early as the first few months of life. We combined antireflux surgery, bladder autoaugmentation, and transvaginal sling suspension in a 3-month-old girl with febrile breakthrough infections, with good clinical and urodynamic result after follow-up for more than 10 years. Initially, reserves existed on doing sling suspensions before puberty, especially in boys, out of fear of introducing obstruction during puberty based on prostate growth. Over the years, it has been proven that puberty can safely be passed after sling suspension of the bladder neck, both in girls and boys.
Parental burden can be an indication for performing a catheterizable stoma. If a child weighs $20 \mathrm{~kg}$, five daily transfers for CIC can be too much for a parent with lower back pain. Finally, the patient's privacy can be an important argumentation for construction of a stoma for CIC. Parents are increasingly reluctant for any caregiver to help their child perform CIC transurethrally, as this involves exposure of the genitalia to strangers several times a day.

\section{Surgery for incontinence}

Patients with a paralytic pelvic floor need bladder-neck surgery to achieve continence. There are many surgical options. Our standard approach is an abdominoperineal puboprostatic sling procedure in boys and a transvaginal sling procedure in girls. If there is some persistent leaking after a sling procedure, this is cured by injecting a bulking agent in the bladder neck. Optimal results are obtained if the injection needle is passed into the bladder neck by means of a suprapubic puncture with transurethral endoscopic visual control. So far, we have mainly used silicon grains in povidone (Macroplastique ${ }^{\circledR}$ ) as a bulking agent. The polymer Deflux ${ }^{\circledR}$ offers a good alternative because it is easier to inject. However, in our experience, Deflux does not work if CIC needs to be carried out through the same channel. A recent survey, yet unpublished, of the results of 76 sling suspensions revealed an $80 \%$ success rate.

\section{Sling suspension in boys}

There is a great variety in the reported results regarding sling suspension of the bladder neck in boys with neuropathic sphincter incompetence, especially when compared with girls. The plane between the bladder neck/ prostate and the rectum must be developed to allow the sling to be wrapped around the bladder neck. There are three possible techniques, each with their specific advantages and disadvantages. First, from the abdominal wound, the pelvic diaphragm can be opened left and right so that a pathway can be bluntly dissected for the sling around the bladder neck. A disadvantage of this technique is the risk of passing into the prostatic urethra with the right angle that is used to feel the way around during surgery. Experienced urologic surgeons do not take this argument seriously, but in practice, most surgeons perform this operation with the relatively low frequency of only a few cases a year. The second possible technique is the abdominoperineal approach to develop the plane between the bladder neck and the urethra. The plane between the rectum and the bladder neck is exposed through a perineal incision. The most important advantages of this procedure are the short time, approximately $20 \mathrm{~min}$, needed to develop the plane around 
the bladder neck and the fact that the bladder does not need to be touched at all [24].

A third method to find the path around the bladder neck has been proposed by Lottmann et al. The complete bladder is dissected from the peritoneum and the rectum until only the urethra and both ureters with the vascular pedicles are left. The sling can easily be passed around the bladder neck, with direct visual control and exactly at the level of the bladder neck [25]. It is difficult to determine which of these three approaches is the best. All three have enthusiastic followers. At our department, we have had two urethral defects treated by two experienced surgeons in a small series of the abdominal approach going directly around the bladder neck. We have had one urethral defect leading to bladder-neck closure in 76 patients operated on abdominoperineally. Our experience with the Lottmann approach is limited to three successful cases and, because of operation time and for fear of limited bladder vascularization, we abandoned this approach.

Another important subject is the amount of tension that needs to be put on the sling. In the past, we tried to regulate tension by measuring urethral and leak-point pressures during surgery, but there was no significant positive outcome. Nowadays, we determine sling tension by measuring the ability to pass a relatively large Foley catheter past the sling; for example, a 12-F catheter in a 7-year-old boy. In some patients with anal atresia after prior rectal pull-through surgery, it may be necessary to adopt the abdominal approach to pass around the bladder neck. Abdominoperineal operations in 14 patients, published in 1999, led to continence in all 14 patients; one patient required a subsequent injection of a bulking agent to help achieve continence [24]. It is important to note that in this series, the erectile function of the penis proved to be preserved after sling suspension.

False routes are a risk after sling suspension. Out of approximately 50 male patients, we had to construct a catheterizable stoma in five: four as a result of a false route, and one because of a huge congenital prostatic cyst.

\section{Sling suspension in girls}

In general, sling suspension of the bladder neck in girls leads to good results concerning urinary continence. There are also several ways to find the way around the bladder neck in girls. The standard well-known technique is to identify the level of the bladder neck by feeling the balloon of a transurethral Foley catheter, and, subsequently, developing the plane between the bladder neck and the anterior vaginal wall from above. This procedure can be very difficult in girls with severe spine deformities. There is always a certain risk of entering the urethra or the bladder neck when passing around. This is also the case in patients with a normal anatomy. To avoid this risk, in postpuberty female patients, many surgeons opt for incising the vaginal wall at the level of the bladder neck and bringing the sling around under direct visual control. We chose to put the sling through the vagina, first only in prepubertal girls and later in all patients. This method has two major advantages: there is no risk of bladder-neck lesions and only a small risk of sling erosion [26]. In spina bifida patients, the risk of sling erosion is higher than in patients with stress incontinence, because the sling must be tightened more strongly in patients with neuropathic sphincter incompetence.

\section{Alternatives}

There are many surgical alternatives for reaching urinary continence. Kropp and Pippi Sale developed operations to create a flap valve from the bladder neck. Young/Deese/ Leadbetter, Tanagho, and Mitchell procedures lengthen the urethra into the bladder. Several authors prefer American Medical Systems (AMS) artificial sphincters to help reach continence. The majority of patients still need CIC after AMS sphincter prosthesis [27]. We found that Burch-type colposuspension was insufficient for spina bifida girls to reach urinary continence. This is related to the huge intraabdominal pressure that can result from transfers from the wheelchair.

Several groups do not opt for urinary continence at an early age and try to maintain safe leak-point pressures by regular dilatation of the female urethra, sometimes also of the male urethra, after making this possible with a perineal urethral stoma. In some patients, they construct a cutaneous vesicostomy for the first few years and perform an ileocystoplasty when the stoma is closed.

\section{Alternatives in dealing with a neurogenic bladder}

When cerebral function is bad and the patient has no dexterity, diapers can also be chosen. For this choice, a low-pressure bladder is necessary. Good results are obtained by cutaneous vesicostomy. In girls, low pressures can be achieved by making a vesicovaginal fistula by endoscopic cutting into the vagina between the ureteric orifices. Temporary low pressures can be achieved by overdistension of the female urethra. In boys, endoscopic external sphincterotomy in the 12 o'clock position produces low outlet resistance for 2-3 years and needs to be repeated when bladder pressures rise.

\section{Catheterizable stomas}

The need for transfers from a wheelchair to do CIC is the most important indication to make a catheterizable stoma. Sometimes in boys, the impossibility of carrying out CIC transurethrally after false routes results in the need for a stoma. Parents increasingly indicate their child's privacy as 
Fig. 1 The appendix can be used to make a stoma to the bladder for intermittent catheterization

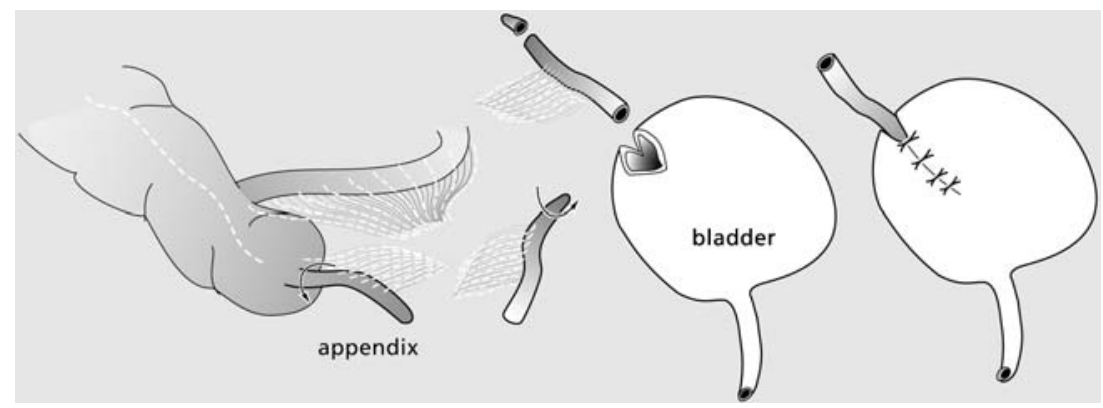

a reason for asking for a catheterizable stoma. In patients with a large bladder capacity for their age, a continent stoma can be constructed from a bladder tube. Patients with a normal bladder capacity can be treated by cutaneous appendicovesicostomy or by an ileal tube (Monti procedure) [28]. The direction of peristalsis from the appendix (Fig. 1) needs to go in the direction of the bladder to avoid mucus spotting in the clothes. When ileal or colonic bladder augmentation is performed at the same time, the continent stoma can be constructed from the side or middle part of the gut used for the augmentation. In some patients, a ureter can be used as a catheterizable stoma. The intravesical tunnel of the tube in the bladder should be at least $2 \mathrm{~cm}$ long, as there is a risk that the tunnel will end up being too short, especially in case of an extravesical implantation of an appendix.

In the literature, after construction of a catheterizable stoma, complications are described in as many as 50\% of patients. These complications are mostly temporary. Stomal stenosis, mostly at skin level, is a frequently occurring temporary complication that can be avoided with a silicon ace stopper left behind in the skin portion of the stoma for 6 months between catheterizations. Stomal leakage of urine can be a frustrating complication. Endoscopic treatment with bulking agents can be tried, but lengthening of the intravesical tunnel or reimplantation of the stoma will often be needed. Leakage of the stoma occurs more often in midline stomas (umbilicus) than in stomas placed on the right side of the lower abdominal wall. The reason is probably that the lateral stoma passes through the rectus muscle and is thus occluded during increases in abdominal pressure due to rectus contraction. In midline stomas we now also pass the stoma through the median margin of one rectus muscle. Stoma stenosis at the level of entrance into the bladder can sometimes be treated endoscopically with success. In those patients, formal reimplantation of the stoma into the bladder will frequently be needed as well.

Autoaugmentation or detrusorectomy of the bladder

In general, not too much extra capacity should be expected, but high-end filling pressures based on low bladder compliance can be reduced to safe values by detrusorec- tomy. In selected patients that undergo surgery to become dry, we also do an autoaugmentation (Fig. 2) to try and get patients off antimuscarinic therapy, with success in approximately $50 \%$ of cases. An important factor for success is identification, opening, and marking the adventitial layers of the bladder separately before the detrusorectomy starts, and the meticulous closure of this layer at the end of the procedure. This means that before the start of the detrusorectomy, the detrusor has been freed of all adventitial layers. If a mucosal leak occurs during the operation, this is closed with Tissuecoll ${ }^{\circledR}$. To prevent shrinkage and scarring, cycling of the bladder has to start immediately after detrusorectomy. This can be done by maintaining a $20-\mathrm{cm} \mathrm{H}_{2} \mathrm{O}$ pressure on day $1,30 \mathrm{~cm}$ on day 2 , followed by clamping the catheter on day 3 for $2 \mathrm{~h}$, and finally by opening the catheter every $3 \mathrm{~h}$ to empty the bladder on following days. In this way, optimal expansion of the detrusorectomized bladder can be obtained [21]. Several authors have reported success by expanding the bladder over a balloon for several days while ensuring drainage of urine by ureteral catheters. We have no experience with this procedure but assume it could work well if there is leakage. Others have successfully covered the bare part of the mucosa with a demucolized patch of sigmoid colon. Covering with peritoneum or omentum has been reported to fail.

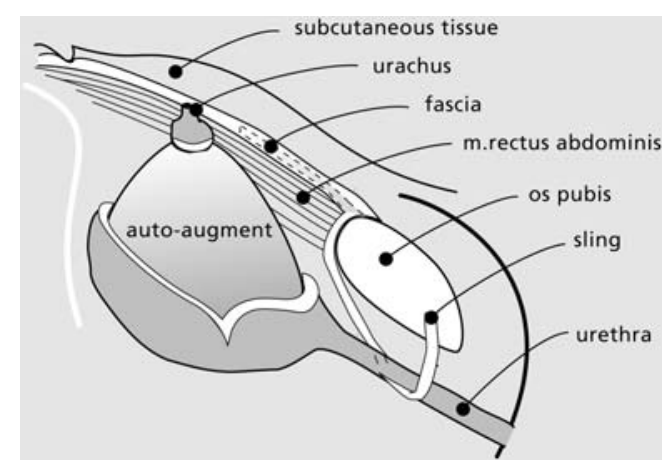

Fig. 2 The bladder can be augmented by removing the detrusor muscle. A sling is used to improve bladder outlet resistance 
Fig. 3 The bladder can be augmented by using a bowel segment

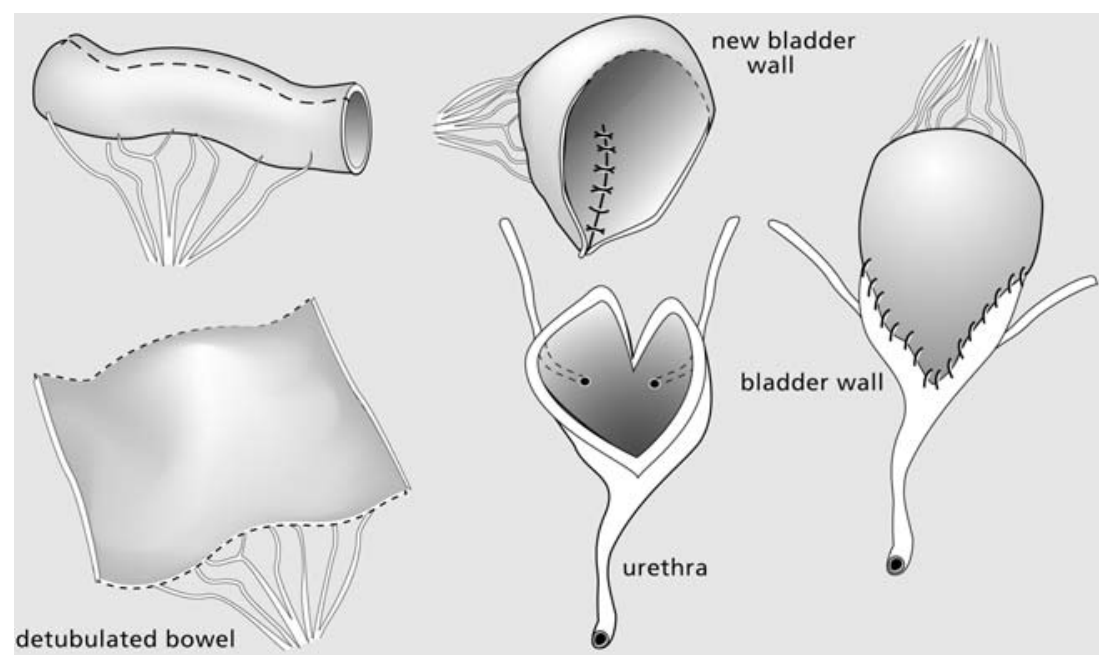

\section{Clam cystoplasty}

Clam cystoplasty (Fig. 3) is indicated when the bladder capacity is too small to reach acceptable numbers of catheterization per day and/or end-filling pressures are too high to be safe for the upper tracts. Clam cystoplasty is performed with either ileum or colon. In general, $25 \mathrm{~cm}$ of ileum are used, opened antimesenterically, and constructed into a U-shaped cap. The last $20 \mathrm{~cm}$ of the ileum are not used, to prevent malabsorption of vitamins. If there is a short ileal mesentery, the sigmoid colon can easily be used. It is important to avoid the formation of an hourglass bladder by opening the clam anteriorly up to the bladder neck and posteriorly up to the trigone. In children, we prefer to bring the augmented bladder extraperitoneally by closing the peritoneum around the vascular pedicle. This extraperitonealization of the bladder may initially make it more difficult to reach sufficient bladder capacity, but it seems to reduce the risk of spontaneous perforation of the bladder, which is a prominent risk in children because of their tendency toward bad CIC compliance during puberty. During a period of several years, we had two spontaneously leaking ileal bladders out of six that had not been placed extraperitoneally, and no spontaneously leaking/rupture in more than 40 other patients with extraperitoneal ileal bladder.

\section{Bowel management and surgery}

For the first 2 years of life, a wait-and-see policy is adopted in bowel management, often supported by chronic use of laxatives. At the age of 3 years, bowel management can be performed successfully in the vast majority of patients with retrograde colonic enemas. The rectum is filled with $20 \mathrm{ml} / \mathrm{kg}$ tap water through a plastic cone that passes approximately $2 \mathrm{~cm}$ into the anus. In the rare case where patients have trouble emptying their rectums with retrograde enemas, we offer an antegrade colonic enema stoma $[29,30]$. A patient's choice can be an indication for an antegrade colonic enema stoma. As a separate procedure, the simplest way to carry out an antegrade colonic enema stoma is to use laparoscopy to bring the tip of the appendix to the abdominal skin (Fig. 4). Alternatives are an open procedure with open abdomen for other surgery or, in the absence of an appendix, to create a transverse tube from the colon (left or right) and a submucosal tunnel to prevent leakage. Many pediatric surgeons and pediatric gastroenterologists have had good experiences with several types of buttons that are put into the colon.

If these procedures are carried out, treatment of spina bifida patients can be very successful. In our experience between 1988 and 2001, the incidence of renal scarring in 144 patients was $2.1 \%$, and urinary dryness in patients who opted to be dry was nearly $80 \%$ [14].

\section{Surgery to improve sexuality in male patients}

Sexuality can be frustrating for male spina bifida patients, because in most cases, they can have intercourse

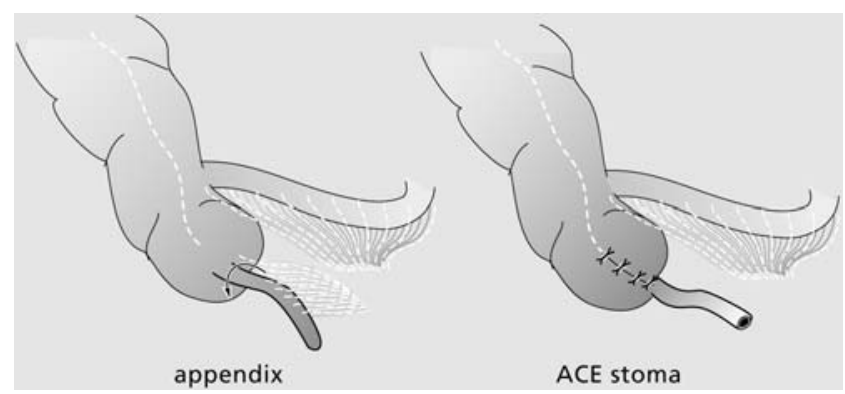

Fig. 4 The appendix can be used to make an antegrade colonic enema stoma 
but penis sensibility is absent. To overcome this, in patients with a lesion under the level of L1, we have connected the ilioinguinal nerve with the dorsal nerve of the penis, resulting in glans sensibility and erogenous feeling in most patients. Patients report a positive effect on sexuality. Our experience with the first three patients has been published, and by now, of 15 cases operated, 12 report normal sensibility of the glans penis [31].

\section{Conclusion}

Kidney-function preservation and early urinary dryness are important factors for optimal quality of life for spina bifida patients. Another important factor is patient independence regarding his or her bladder and bowel management. For optimal treatment of this difficult group of patients, a multidisciplinary team is needed consisting of members from all the necessary medical specialties, including rehabilitation specialists, physical therapists, specialized nurses, and social workers.

\section{Questions}

(Answers appear following reference list)

1. Concerning renal scarring and renal failure in spina bifida literature:

a. Reported death rate due to renal failure is up to $20 \%$ in the first year of life

b. Reported renal failure rate is up to $20 \%$ in the first year of life

c. Reported death rate due to renal failure is up to $20 \%$ in puberty

d. Reported renal failure rate is up to $20 \%$ in puberty

2. Concerning clean intermittent catheterization (CIC):

a. CIC is best started immediately after closure of the spinal defect

b. CIC is best started immediately after the age of 8-9 years

c. CIC is best started not earlier than after bladder neck surgery

d. CIC is best started not earlier than after several urinary infections and reported renal scarring

3. Infection prophylaxis in spina bifida patients:

a. All patients need low-dose chemoprophylaxis

b. Fifteen percent of all patients need low-dose chemoprophylaxis

c. Scientific proof of the need for infection prophylaxis is still lacking

d. No patients need low-dose chemoprophylaxis
4. In case of hyperactive detrusor muscle in a patient with spina bifida:

a. Central side-effects occur less frequently if antimuscarinic therapy is administered orally

b. Antimuscarinic therapy is the gold standard for pharmaceutical therapy

c. Repeated injection therapy of the bladder with only $3 \mathrm{U}$ of botulinum toxin can be an alternative to antimuscarinic therapy

d. Antimuscarinic therapy has positive effects on perspiration and body-temperature regulation

5. In modern management of spina bifida, endpoint targets are:
a. Kidney-function preservation
b. Dryness
c. Fecal continence
d. All the above

\section{References}

1. Holzbeierlein J, Pope JC IV, Adams MC, Bruner J, Tulipan N, Brock JW III (2000) The urodynamic profile of myelodysplasia in childhood with spinal closure during gestation. J Urol 164 (4):1336-1339

2. Pal-de Bruin KM, Buitendijk SE, Hirasing RA, den Ouden AL (2000) Prevalence of neural tube defects in births before and after promotion of periconceptional folic acid supplementation. Ned Tijdschr Geneeskd 144(36):1732-1736

3. Wen SW, Liu S, Joseph KS, Rouleau J, Allen A (2000) Patterns of infant mortality caused by major congenital anomalies. Teratology 61(5):342-346

4. Singhal B, Mathew KM (1999) Factors affecting mortality and morbidity in adult spina bifida. Eur J Pediatr Surg 9(Suppl 1):31-32

5. Greig JD, Young DG, Azmy AF (1991) Follow-up of spina bifida children with and without upper renal tract changes at birth. Eur J Pediatr Surg 1(1):5-9

6. Lawrenson R, Wyndaele JJ, Vlachonikolis I, Farmer C, Glickman S (2001) Renal failure in patients with neurogenic lower urinary tract dysfunction. Neuroepidemiology 20(2):138-143

7. Little DM, Gleeson MJ, Hickey DP, Donovan MG, Murphy DM (1994) Renal transplantation in patients with spina bifida. Urology 44(3):319-321

8. Van Gool JD (1984) Vesicoureteral reflux in children with spina bifida and detrusor-sphincter dyssynergia. Contrib Nephrol 39:221-237

9. Glott T, Stanghelle JK, Rand-Hendriksen S, Thyberg M, Melhus M, Braband K, Fjeld JG, Bakke A (2001) Follow-up of urinary tract problems in adults with myelomeningocele. Tidsskr Nor Laegeforen 121(10):1247-1251

10. Bauer SB, Colodny AH, Retik AB (1982) The management of vesicoureteral reflux in children with myelodysplasia. J Urol 128 (1):102-105

11. Gordon I (1995) Vesico-ureteric reflux, urinary-tract infection, and renal damage in children. Lancet 346(8973):489-490

12. Brown S, Marshall D, Patterson D, Cunningham AM (1999) Chronic pyelonephritis in association with neuropathic bladder. Eur J Pediatr Surg 9(Suppl 1):29-30 
13. Martinell J, Claesson I, Lidin-Janson G, Jodal U (1995) Urinary infection, reflux and renal scarring in females continuously followed for 13-38 years. Pediatr Nephrol 9:131-136

14. Muller T, Arbeiter K, Aufricht C (2002) Renal function in myelomeningocele: risk factors, chronic renal failure, renal replacement therapy and transplantation. Curr Opin Urol 12(6):479-484

15. Dik P, Klijn AJ, van Gool JD, de Jong-de Vos van Steenwijk CC, De Jong TP (2006) Early start to therapy preserves kidney function in spina bifida patients. Eur Urol 49:908-913

16. Hopps C, Kropp K (2003) Preservation of renal function in children with myelomeningocele managed with basic newborn evaluation and close follow-up. J Urol 169:305-308

17. Lapides J, Diokno AC, Silber SM, Lowe BS (2002) Clean, intermittent self-catheterization in the treatment of urinary tract disease, 1972. J Urol 167(4):1584-1586

18. Kasabian NG, Bauer SB, Dyro FM, Colodny AH, Mandell J, Retik AB (1992) The prophylactic value of clean intermittent catheterization and anticholinergic medication in newborns and infants with myelodysplasia at risk of developing urinary tract deterioration. Am J Dis Child 146(7):840-843

19. Lin-Dyken DC, Wolraich ML, Hawtrey CE, Doja MS (1992) Follow-up of clean intermittent catheterization for children with neurogenic bladders. Urology 40(6):525-529

20. Van Gool JD, De Jong TP, Boemers TM (1991) Effect of intermittent catheterization on urinary tract infections and incontinence in children with spina bifida. Monatsschr Kinderheilkd 139(9):592-596

21. Dik P, Tsachouridis GD, Klijn AJ, Uiterwaal CSPM, de Jong TPVM (2003) Detrusorectomy for neuropathic bladder in patients with spinal dysraphism. J Urol 170:1351-1354

22. Ab E, Dik P, Klijn AJ, van Gool JD, de Jong TP (2004) Detrusor overactivity in spina bifida: how long does it need to be treated? Neurourol Urodyn 23(7):685-688

23. Riccabona M, Koen M, Schindler M, Beckers G, Pycha A, Lusuardi L, Bauer SB (2004) Botulinum-A toxin injection into the detrusor: a safe alternative in the treatment of children with myelomeningocele with detrusor hyperreflexia. J Urol 171(2 Pt 1): 845-848

24. Dik P, Van Gool JD, De Jong TP (1999) Urinary continence and erectile function after bladder neck sling suspension in male patients with spinal dysraphism. BJU Int 83(9):971-975
25. Lottmann H, Traxer O, Aigrain Y, Melin Y (1999) Posterior approach to the bladder for implantation of the 800 AMS artificial sphincter in children and adolescents: techniques and results in eight patients. Ann Urol (Paris) 33(5):357-363

26. Dik P, Klijn AJ, van Gool JD, de Jong TP (2003) Transvaginal sling suspension of bladder neck in female patients with neurogenic sphincter incontinence. J Urol 170(2 Pt 1):580-581; discussion 581-582

27. Snyder HM, Arap S, Bloom D, Fisch M, Gonzalez R, Mitchell M, Nijman R, Woodhouse C (1999) Bladder outlet reconstruction in children for continence and dryness. In: Abrams P, Khoury S, Wein AJ (eds). Incontinence, Health Publication, Plymouth, pp 566-571

28. Lemelle JL, Simo AK, Schmitt M (2004) Comparative study of the Yang-Monti channel and appendix for continent diversion in the Mitrofanoff and Malone principles. J Urol 172(5 Pt 1):19071910

29. Roberts JP, Moon S, Malone PS (1995) Treatment of neuropathic urinary and faecal incontinence with synchronous bladder reconstruction and the antegrade continence enema procedure. Br J Urol 75(3):386-389

30. Schöller-Gyüre $M$, Nesselaar C, van Wieringen $H$, van Gool JD (1996) Treatment of defecation disorders by colonic enemas in children with spina bifida. Eur J Pediatr Surg 6(Suppl 1): 32-34

31. Overgoor ML, Kon M, Cohen-Kettenis PT, Strijbos SA, de Boer N, de Jong TP (2006) Neurological bypass for sensory innervation of the penis in patients with spina bifida. J Urol 176 (3):1086-1090
1. a
2. a
3. c
4. b
5. d

Answers: 